\title{
SCIDiC
}

\author{
International Journal of Dentistry and Oral Science (IJDOS) \\ ISSN: 2377-8075
}

\section{Ecofriendly Synthesis, Characterisation and Antibacterial Activity Of Curcumin Mediated Silver Nanoparticles}

Research Article

Sreedevi Dharman ${ }^{1 *}$, Maragathavalli ${ }^{2}$, Rajeshkumar ${ }^{3}$, Karpagavalli Shanmugasundaram $^{4}$

${ }^{1}$ Reader, Department of Oral Medicine \& Radiology Saveetha Dental College, Saveetha Institute of Medical and Technical Sciences No.162, Poonamalle High Road, Chennai-600077 Tamil Nadu, India.

${ }^{2}$ Professor \& Head, Department of Oral Medicine \& Radiology Saveetha Dental College, Saveetha Institute of Medical and Technical Sciences.

${ }^{3}$ Associate Professor, Nanobiomedicine Lab Department of Pharmacology, Saveetha Dental College, Saveetha Institute of Medical and Technical Sciences.

${ }^{4}$ Professor \& Head, Department of Oral Medicine \& Radiology Seema Dental College \& Hospital Rishikesh.

Abstract

Curcumin is the main phytochemical present in the rhizome curcuma longa Linn. Inspite of its therapeutic efficacy, poor bioavailability due to low absorption, rapid metabolism and elimination deters its beneficial action. Efficient drug delivery system for curcumin is warranted which is achieved by nanoparticle synthesis. This research aimed to prepare and characterise curcumin mediated silver nanoparticles and to evaluate its antibacterial activity against oral pathogens. Biosynthesis of Curcumin mediated silver nanoparticles were achieved when curcumin reduced silver nitrate to silver atom. Characterisation were done by UV-visible absorption spectroscopy (UV-Vis) and Transmission electron microscopy (TEM). Evaluation of antibacterial activity against oral pathogens were performed in Staphylococcus aureus, Streptococcus mutans (Gram positive bacteria), E. coli, Enterococcus sp (Gram negative bacteria). On visual observation, colour change from initial yellow solution to dark brown within 1 hour of reaction time, absorbance peak at $430 \mathrm{~nm}$ ascertained curcumin mediated silver nanoparticles synthesis. Curcumin had reducing and capping action. TEM revealed spherical and triangular structure with diameter ranging from 5-70 $\mathrm{nm}$. They showed superior antibacterial activity against oral pathogens such as as $\mathrm{S}$. mutans, moderate activity against $\mathrm{S}$. aureus, E. coli and Enterococcus sp in concentration of $50-\mu \mathrm{g} \mathrm{mL}$ - 1hence proving its effective broad spectrum antibacterial activity which can be applied in various oral mucosal lesions with infectious disease with minimal side effects.

Keywords: Curcumin; Silver Nanoparticles; UV-VIS Spectroscopy; TEM; Antibacterial; Oral Mucosal Lesions.

\section{Introduction}

Oral infections consist of mixed populations of aerobic and anaerobic bacteria, pose risk of development of resistance with improper use of multiple antimicrobials [1]. Also oral bacteria enters blood stream through ulcerated epithelium causes bacteremia or septicemia, is a risk for immuno compromised patients [2]. Resistance of antibiotics worldwide pose a great threat and necessitates for research and discovery of new antimicrobials. As 7 lakh people die due to drug resistant infections and if necessary measures are not taken may kill 10 million people by 2050 [3]. An alternative antimicrobial therapy to treat oral infectious disease with lesser side effects is achieved through phytochemicals via green synthesis nanotechnology.

Nanobiotechnology is a multifaceted research area comprising biology, medicine and material engineering. Its goal is to produce safe, ecofriendly nanoparticles useful for therapeutic functions by a method called Green synthesis [4]. Green Synthesis is the production of nanoparticles using plant extracts and its bio com-

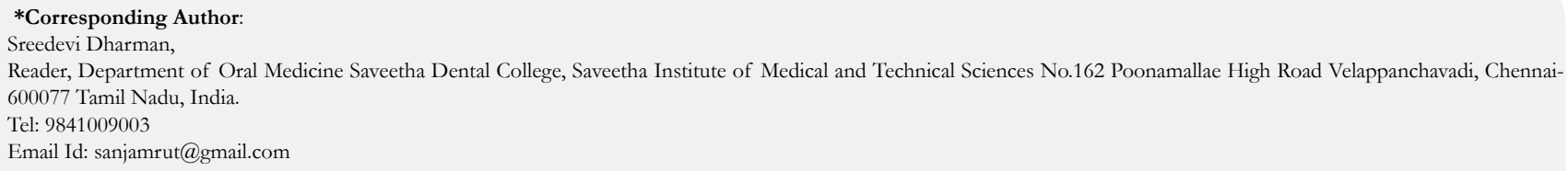

Received: March 11, 2021

Accepted: April 09, 2021

Published: April 14, 2021

Citation: Sreedevi Dharman, Maragathavalli, Rajeshkumar, Karpagavalli Shanmugasundaram. Ecofriendly Synthesis, Characterisation and Antibacterial Activity Of Curcumin Mediated Silver Nanoparticles. Int J Dentistry Oral Sci. 2021;08(04):2314-2318. doi: http://dx.doi.org/10.19070/2377-8075-21000457

Copyright: Sreedevi Dharman 2021 . This is an open-access article distributed under the terms of the Creative Commons Attribution License, which permits unrestricted use, distribution and reproduction in any medium, provided the original author and source are credited. 
pounds applied for various medicinal therapies like antimicrobial, anti-inflammatory, anticancer and antioxidant [5]. In the past few decades tremendous interest is directed towards biomedical evaluation of metallic nanoparticles derived from noble metals such as silver, gold for its chemical, biological and physical properties [6].

Silver Nanoparticles have good antimicrobial properties, can be effectively used against Multi-Drug Resistant microorganisms [7]. Silver nanoparticles are more favorable due to their high precise toxicity towards bacteria, less toxicity towards individuals. Silver Nanoparticles are prepared by different techniques such as physical, biological and chemical methods [8]. Plant-mediated preparation of nanoparticles has a distinct dimension, structure, and form than alternative physical and chemical methodologies $[9,10$, $11,12,13]$. Surface charge density, more surface to volume ratio, spherical shaped, small, lesser degree clumped are considered to be more effective properties of silver nanoparticles [14]. Phytochemicals show an evident part in reducing and stabilising metal nanoparticles [15]. Curcumin possesses potent antioxidant, antiinflammatory, antitumor and antimicrobial properties [16]. They have various medicinal property with superior safety profile but administration has practical problem. Poor bioavailability, Rapid metabolism, limited absorption are its drawbacks [17]. Huge dosage have to be swallowed to reach the substantial concentration. To solve these problems, nanoparticle-based drug delivery approaches are the right choice to enhance the wider medicinal applications of curcumin [18]. These materials have the ability to penetrate cells, translocate to other cells, tissues, organs distant from portal of entry to the body [19], thus improving its bioavailability potential helpful in treating various oral diseases.

To the finest of our understanding, the antibacterial action of curcumin mediated silver nanoparticles by green synthesis on oral pathogens are not studied before, hence our present research aimed to develop original method of curcumin assisted silver nanoparticles and its evaluation of its antibacterial effect.

\section{Materials and Methods}

\section{Materials:}

Curcumin, silver nitrate and bacterial media were commercially purchased from Hi Media, Mumbai.

\section{Silver Nanoparticles Synthesis:}

$10 \mathrm{mM}$ of curcumin was added with $25 \mathrm{ml}$ of distilled water. 75 $\mathrm{ml}$ of $1 \mathrm{mM}$ of silver nitrate solution was mixed with curcumin solution and kept in magnetic stirrer. The color transference was visually observed when $\mathrm{Ag}+$ from $\mathrm{AgNO} 3$ are reduced and converted to $\mathrm{AgO}$, which are evaluated by $\mathrm{UV}$-vis spectroscopic scanning from $320-560 \mathrm{~nm}$.

\section{Purification and Characterisation Of Silver Nanoparticles:}

Purification was done by centrifugation of synthesised silver nanoparticles at $6500 \mathrm{rpm}$ for $15 \mathrm{~min}$ and the process is repeated thrice and washed by using double distilled water. After discarding the supernatant the pellet is dried in hot air oven at $60^{\circ} \mathrm{C}$ for 15 min colloidal nanoparticle solution and powdered Curcumin Silver Nanoparticles are obtained. The nanoparticle powder is characterised by TEM and it provides more understanding in to the morphology, dimension details of the silver nanoparticles.

\section{Antibacterial Activity:}

Evaluation of antibacterial property of silver nanoparticles were done against oral pathogenic gram positive and gram negative bacteria using Agar Well diffusion. Varying concentrations of synthesized nanoparticles were studied against the oral pathogenic bacteria like S. mutans, E. coli, Enterococcus sp and S. aureus. Silver nanoparticles with varying concentratin of $50,100,150 \mu \mathrm{L}$ were added to wells and Amoxicillin used as positive control in Muller-Hinton agar plates. Incubating the plates for 24 hours at $37^{\circ} \mathrm{C}$ were done, and the inference were noted by gauging the diameter of the zone of inhibition in millimeters.

\section{Results and Discussion}

\section{Curcumin Assisted Silver Nanoparticle Characterisation:}

\section{Visual Examination and UV-vis Spectroscopy Scanning}

Silver nitrate during reaction with aqueous extract of curcumin was tracked by the color transference from initial yellow solution to dark brown color within 1 hour of reaction time indicating the nanoparticle formation (Figure $1 \mathrm{a}, \mathrm{b}$ ). Appearance of dark brown color is because of surface plasmon resonance of silver nanoparticles. The ultraviolet-visible spectroscopy scanning of the solution with silver nanoparticles exhibited an absorption peak at around $430 \mathrm{~nm}$ which preliminarily confirmed silver nanoparticle synthesis (Figure 2). [20], reported faster silver nanoparticles synthesis from $\mathrm{M}$. oleifera by 10 minutes at $60^{\circ} \mathrm{C}-80^{\circ} \mathrm{C}{ }^{20}$. Haneefa et al, in Manganese Nanoparticles synthes is reduction of manganese metal salt was confirmed by change in color detected from

Figure 1a,b. Visual color difference of reaction mixture containing curcumin solution with silver nitrate at 0 hour (a)and 1 hour (b).

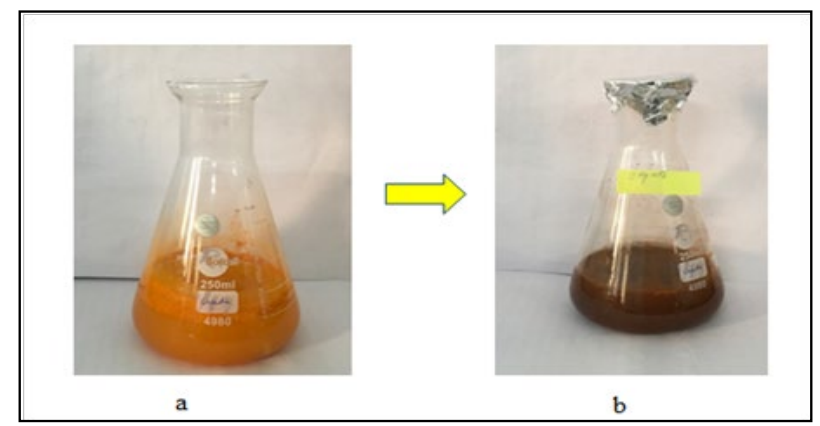


pale green to pale yellow, and the stabilization of MONPs was noticed by the color transference from yellowish to permanent reddish brown. Manganese was reduced by lemon extracts, curcumin was the capping agent, biofunctionalised material used was chitosan [21]. In our study curcumin is the reducing and capping agent in silver nanoparticle preparation. Roy et al in her study, addition of neem extract initially showed pale yellow to light brown, increasing the incubation time turned to deep brown after 24 hours. Variation in peak absorbance was due to variation in particle size. Peak absorbance were $430 \mathrm{~nm}$, in which smaller particles absorb UV rays in electromagnetic range revealing nanoparticles unique optical property, which was similar to our study where the ultraviolet-visible band of the curcumin assisted silver nanoparticles solution exhibited the peak of absorbance at around $430 \mathrm{~nm}$ which preliminarily confirmed the silver nanoparticles synthesis [22]. Yangqing $\mathrm{He}$ et al in his study, reaction time after 8 days in synthesis of silver nanoparticles are reported, indicating the slow synthesis, $417 \mathrm{~nm}$ slightly shifted to $436 \mathrm{~nm}$ during the reaction, higher rate of sudden nucleation significantly speeded the growth rate of silver nanoparticles [23]. The time needed for formation of nanoparticle synthesis varied depending on character of the reducing agent [24]. (Figure 3a,b) shows colloidal nanoparticle solution and powdered Curcumin Silver Nanoparticles.

\section{TEM Analysis:}

In our study, different shapes of nanoparticles such as spherical, triangular and rectangular shaped are well dispersed formed in the size range from 5-70 nm, also shows capping of curcumin with silver nanoparticles (Figure 4 a,b). In TEM Analysis silver nanoparticles which are spherical in shape exhibit superior antimicrobial activity when compared to rod shape, small particle has better bioactivity than larger ones. Heat reduces the size of nanoparticles, heat driven nanoparticle synthesised from M. oleifera leaf were $57 \mathrm{~nm}$ [20]. Silver nanoparticle synthesis from Allium sativum, Andrachea chordfolia with use of sunlight resulted in 7.3 $\mathrm{nm}, 3.4 \mathrm{~nm}$ [24]. Most of the silver nanoparticles were eclipsed and spherical form with considerable particle measurement from $50 \mathrm{~nm}$ and some of nanoparticles nearly $100 \mathrm{~nm}$ [25].

\section{Antibacterial Activity:}

Silver nanoparticles prepared by curcumin showed higher antibacterial effect against oral pathogens like S. mutans moderate antibacterial action against E. coli, S. aureus and Enterococcus sp (Figure 5a, b, c, d). Our study results indicated that curcumin mediated silver nanoparticles synthesized were not only efficacious at lesser concentrations, but they even exhibit good zone of inhibition against commercially available antibiotic Amoxicillin. All the four strains of bacteria showed sensitivity to Amoxicillin $5 \mu \mathrm{g} / \mathrm{mL}$. Zone of Inhibition for Different Concentrations of Curcumin Silver Nanoparticles by Oral Pathogens are shown as Bar diagram in Figure 6. Silver nanoparticles cling to the cell membrane, reducing respiratory role, oxidized nanoparticles induce hole formation on surface of bacteria enhancing bactericidal activity [26]. M. oleifera leaf derived silver nanoparticles showed MIC antimicrobial inhibition for Bacterial strains as 12.5-25 $\mu \mathrm{g} /$ mland fungal strains were $6.25 \mu \mathrm{g} / \mathrm{ml}$ which exhibited broader spectrum of antibacterial activity [24]. In our study, silver nanoparticles synthesised using curcumin showed broader antibacterial potential in $50 \mu \mathrm{g} / \mathrm{ml}$. Thick peptidoglycan layer is present in gram-positive bacteria that has plasma membrane as cell wall, lacking the outer membrane compared to gram-negative bacteria that has rigid cell wall consisting of lipids and lipoproteins [27]. This could have been the reason why curcumin assisted silver nanoparticles had difficulty to enter and interact with cellular components of gram negative bacteria such as E.coli ,Enterocoous thus showing lesser degree of inhibition. In our study both

Figure 2. UV-vis spectrum of silver nanoparticles synthesized from Curcumin showing absorbance peak and blank solution after 1 hour of reaction.

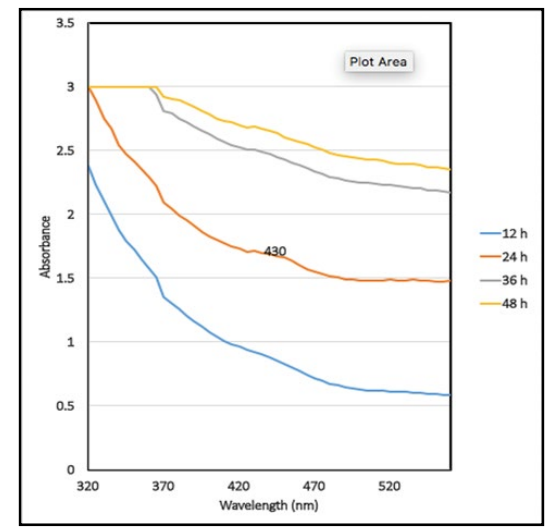

Figure 3a,b. shows colloidal nanoparticle solution and powdered Curcumin Silver Nanoparticles.

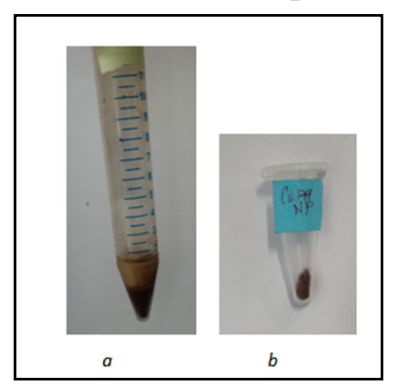


Figure 4 a,b. TEM Images of silver nanoparticles produced from Curcumin.

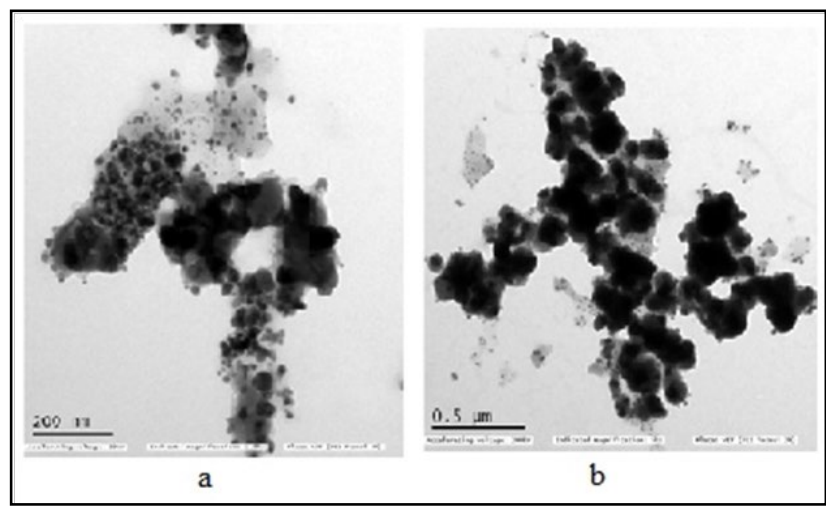

Figure 5a, b, c, d. Shows good antibacterial activity against Streptococcus mutans, medium antibacterial effect towards Staphylococcus aureus, E. coli and Enterococcus.

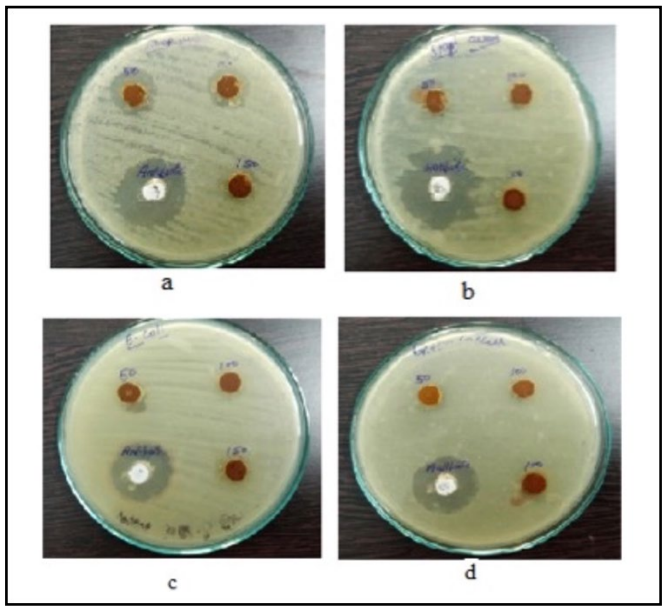

Figure 6. Bar diagram shows zone of inhibition in $\mathrm{mm}$ for different concentrations of curcumin mediated silver nanoparticles by various oral pathogens.

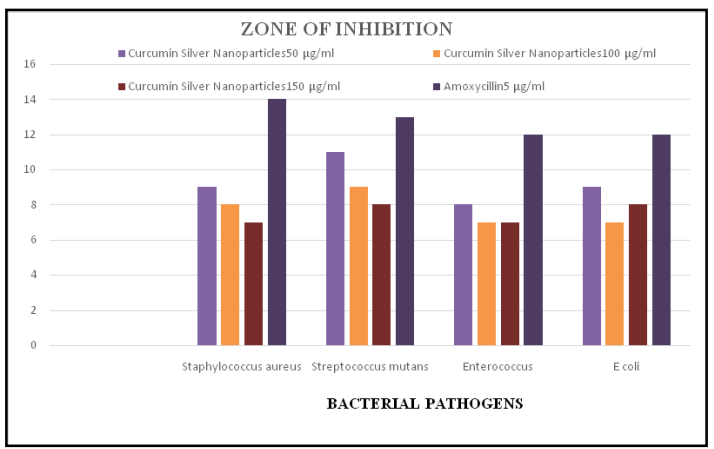

gram positive and gram negative bacteria were inhibited, with more susceptibility was exhibited by gram positive bacteria such as S.mutans, S.aureus. In contrast to a study done with D-glucose and hydrazine as a reducing agent in silver nanoparticles synthesis, effective inhibition was by gram negative bacteria [28]. Silver nanoparticles synthesis by Azadirachta indica [22] at $3 \mathrm{ml}$ plant extract, $10 \mathrm{ml}$ silver nanoparticles showed Zone of inhibition size of $11.83 \mathrm{~mm}$ at $50 \mu \mathrm{g} /$ mlagainst e coli when compared to our study antibacterial activity against $\mathrm{S}$. mutans were $11 \mathrm{~mm}$ at $50 \mu \mathrm{g} / \mathrm{ml}$. In Alpinia katsumadai silver nanoparticle synthesis minimum inhibitory concentration noticed for E. coli, S. aureus are $20 \mathrm{mg} /$ $\mathrm{ml}$, P. aeruginosa $40 \mu \mathrm{g} / \mathrm{ml}$,S.mutans $50 \mu \mathrm{g} / \mathrm{ml}$ [23]. Bar diagram shows zone of inhibition in $\mathrm{mm}$ for different concentrations of curcumin mediated silver nanoparticles by various oral pathogens. (Figure 6). Silver cations adheres to bacterial cell wall which is negatively charged and burst them causing protein denaturation, affecting the replication of DNA and eventual cell death [29]. Bacterial cell is in the micrometre range, outer cellular membranes contain pores in the nanometer range. Nanoscale materials enter the cells of bacteria and make lethal oxygen radicals, results in microbial cellular membrane damage leading to strong inhibition of the growth of bacteria. [21]. In our study, Curcumin mediated silver nanoparticle by green synthesis showed pronounced antibacterial activity against gram positive bacteria when compared to gram negative. Combining curcumin with that of silver ions is beneficial to minimise the dose need to be administered for total microbial reduction. The present research reveals the antibacterial activity of silver nanoparticles prepared from curcumin by a cost effective, ecofriendly green synthesis. This improves the bioavailability of curcumin that is converted in to Nanoformulation with 
reduced dosage can be used as topically in various oral diseases thus reducing the side effects caused by routine antibiotics and other conventional therapies.

\section{Conclusion}

It is concluded that curcumin assisted silver nanoparticles have great role and has high antibacterial activity, hence resisting bacterial growth in lesser drug concentration. The present research work suggests the environment friendly, biocompatible technique for preparation of silver nanoparticles by green synthesis methodologies from bio compound curcumin which is stabilizing and reducing agent. The UV-Vis, TEM study ensured the formation of nanoparticles. Rapid synthesis, small sized 5-70 nm spherical, triangular shaped silver nanoparticles is an effective antibacterial agent against $\mathrm{S}$. mutans, moderate against other disease causing pathogens.

\section{Clinical Significance}

Biosynthesised nanoparticles were characterised and exhibited their potential use in oral infectious diseases. Curcumin assisted silver nanoparticles are cost effective.

\section{Acknowledgments}

We thank the Nanobiomedicine lab, Saveetha dental college \& Hospital for giving the facilities to complete this work.

\section{References}

[1]. Simôes M. Antimicrobial strategies effective against infectious bacterial biofilms. Curr Med Chem. 2011:18(14):2129-45. Pubmed PMID: 21517762.

[2]. Asikainen S, Alaluusua S. Bacteriology of dental infections. Eur Heart J. 1993 Dec;14 Suppl K:43-50. Pubmed PMID: 8131787.

[3]. WHO names 12 bacteria that pose the greatest threat to human health. The Guardian, 2017 (https://www.theguardian.com/society/2017/feb/27/worldhealth-organisation-12-antibiotic-resistant-bacteria-threat-human-health, accessed 7 March 2017).

[4]. Singh P, Kim YJ, Zhang D, Yang DC. Biological Synthesis of Nanoparticles from Plants and Microorganisms. Trends Biotechnol. 2016 Jul;34(7):588599. Pubmed PMID: 26944794.

[5]. Castro-Aceituno V, Ahn S, Simu SY, Singh P, Mathiyalagan R, Lee HA, et al. Anticancer activity of silver nanoparticles from Panax ginseng fresh leaves in human cancer cells. Biomed Pharmacother. 2016 Dec;84:158-165. Pubmed PMID: 27643558.

[6]. Mohanpuria P, Rana NK, Yadav SK. Biosynthesis of nanoparticles: technological concepts and future applications. Journal of nanoparticle research. $2008 \mathrm{Mar} ; 10(3): 507-17$.

[7]. Wang C, Mathiyalagan R, Kim YJ, Castro-Aceituno V, Singh P, Ahn S, et al. Rapid green synthesis of silver and gold nanoparticles using Dendropanax morbifera leaf extract and their anticancer activities. Int J Nanomedicine. 2016 Aug 10;11:3691-701. Pubmed PMID: 27570451.

[8]. Hajipour MJ, Fromm KM, Ashkarran AA, Jimenez de Aberasturi D, de Larramendi IR, Rojo T, et al. Antibacterial properties of nanoparticles. Trends Biotechnol. 2012 Oct;30(10):499-511. Pubmed PMID: 22884769.

[9]. Kumar R, Ghoshal G, Jain A, Goyal M. Rapid green synthesis of silver nanoparticles (AgNPs) using (Prunus persica) plants extract: exploring its antimicrobial and catalytic activities. J Nanomed Nanotechnol. 2017;8(4):1-8.

[10]. Menon S, Agarwal H, Rajeshkumar S, Kumar SV. Anticancer assessment of biosynthesized silver nanoparticles using Mucuna pruriens seed extract on Lung Cancer Treatment. Research Journal of Pharmacy and Technology. 2018 Sep 1;11(9):3887-91.
[11]. Happy Agarwal, Soumya Menon, Venkat Kumar S, Rajeshkumar S. Mechanistic study on antibacterial action of zinc oxide nanoparticles synthesized using green route. Chem Biol Interact. 2018 Apr 25;286:60-70. Pubmed PMID: 29551637.

[12]. Rajeshkumar S, Bharath LV. Mechanism of plant-mediated synthesis of silver nanoparticles - A review on biomolecules involved, characterisation and antibacterial activity. Chem Biol Interact. 2017 Aug 1;273:219-227. Pubmed PMID: 28647323.

[13]. Rajeshkumar S, Kumar SV, Ramaiah A, Agarwal H, Lakshmi T, Roopan SM. Biosynthesis of zinc oxide nanoparticles usingMangifera indica leaves and evaluation of their antioxidant and cytotoxic properties in lung cancer (A549) cells. Enzyme Microb Technol. 2018 Oct;117:91-95. Pubmed PMID: 30037558.

[14]. Singh P, Kim YJ, Zhang D, Yang DC. Biological Synthesis of Nanoparticles from Plants and Microorganisms. Trends Biotechnol. 2016 Jul;34(7):588599. Pubmed PMID: 26944794.

[15]. Singh P, Kim YJ, Singh H, Wang C, Hwang KH, Farh Mel-A, et al. Biosynthesis, characterization, and antimicrobial applications of silver nanoparticles. Int J Nanomedicine. 2015 Mar 31;10:2567-77. Pubmed PMID: 25848272.

[16]. Wang P, Su C, Li R, Wang H, Ren Y, Sun H, et al. Mechanisms and effects of curcumin on spatial learning and memory improvement in APPswe/PS1dE9 mice. J Neurosci Res. 2014 Feb;92(2):218-31. Pubmed PMID: 24273069.

[17]. Anand P, Kunnumakkara AB, Newman RA, Aggarwal BB. Bioavailability of curcumin: problems and promises. Mol Pharm. 2007 Nov-Dec;4(6):807-18. Pubmed PMID: 17999464.

[18]. Anand P, Nair HB, Sung B, Kunnumakkara AB, Yadav VR, Tekmal RR, et al. RETRACTED: Design of curcumin-loaded PLGA nanoparticles formulation with enhanced cellular uptake, and increased bioactivity in vitro and superior bioavailability in vivo.

[19]. Bhawana, Basniwal RK, Buttar HS, Jain VK, Jain N. Curcumin nanoparticles: preparation, characterization, and antimicrobial study. J Agric Food Chem. 2011 Mar 9;59(5):2056-61. Pubmed PMID: 21322563.

[20]. Prasad TN, Elumalai EK. Biofabrication of Ag nanoparticles using Moringa oleifera leaf extract and their antimicrobial activity. Asian Pac J Trop Biomed. 2011 Dec;1(6):439-42. Pubmed PMID: 23569809.

[21]. Haneefa MM. Green synthesis characterization and antimicrobial activity evaluation of manganese oxide nanoparticles and comparative studies with salicylalchitosan functionalized nanoform. Asian Journal of Pharmaceutics (AJP): Free full text articles from Asian J Pharm. 2017 Mar 21;11(01).

[22]. Roy P, Das B, Mohanty A, Mohapatra S. Green synthesis of silver nanoparticles using Azadirachta indica leaf extract and its antimicrobial study. Applied Nanoscience. 2017 Nov;7(8):843-50.

[23]. He Y, Wei F, Ma Z, Zhang H, Yang Q, Yao B, et al. Green synthesis of silver nanoparticles using seed extract of Alpinia katsumadai, and their antioxidant, cytotoxicity, and antibacterial activities. RSC advances. 2017;7(63):3984251.

[24]. Moodley JS, Krishna SB, Pillay K, Govender P. Green synthesis of silver nanoparticles from Moringa oleifera leaf extracts and its antimicrobial potential. Advances in Natural Sciences: Nanoscience and Nanotechnology. 2018 Mar 9;9(1):015011.

[25]. Rajeshkumar S, Malarkodi C, Venkat-Kumar S. Synthesis and characterization of silver nanoparticles from marine brown seaweed and its antifungal efficiency against clinical fungal pathogens. Asian J. Pharmaceut. Clin. Res. 2017;10(2):190-3.

[26]. Smetana AB, Klabunde KJ, Marchin GR, Sorensen CM. Biocidal activity of nanocrystalline silver powders and particles. Langmuir. $2008 \mathrm{Jul}$ 15;24(14):7457-64. Pubmed PMID: 18543995.

[27]. Ebrahiminezhad A, Bagheri M, Taghizadeh SM, Berenjian A, Ghasemi Y. Biomimetic synthesis of silver nanoparticles using microalgal secretory carbohydrates as a novel anticancer and antimicrobial. Advances in Natural Sciences: Nanoscience and Nanotechnology. 2016 Mar 18;7(1):015018.

[28]. Shrivastava S, Bera T, Roy A, Singh G, Ramachandrarao P, Dash D. Characterization of enhanced antibacterial effects of novel silver nanoparticles. Nanotechnology. 2007 May 4;18(22):225103.

[29]. Yu-sen EL, Vidic RD, Stout JE, McCartney CA, Victor LY. Inactivation of Mycobacterium avium by copper and silver ions. Water Research. 1998 Jul 1;32(7):1997-2000. 